\title{
Molybdenum Blue Spectrophotometry for Trace Arsenic in Ground Water Using a Soluble Membrane Filter and Calcium Carbonate Column
}

\author{
Takuya OKaZaKi, Wenjing WANG, Hideki KuRAmitz, Noriko Hata, and Shigeru TAGUCHI ${ }^{\dagger}$ \\ Department of Environmental Biology and Chemistry, Graduate School of Science and Engineering for \\ Research, University of Toyama, Gofuku 3190, Toyama 930-8555, Japan
}

\begin{abstract}
An improved molybdenum blue spectrophotometry using a soluble membrane filter and $\mathrm{CaCO}_{3}$-column was proposed for determining arsenic in drinking water supplied from ground water in the presence of phosphate. A $100 \mathrm{~mL}$ sample solution containing $0.5-10 \mu \mathrm{g}$ arsenic was passed through a $\mathrm{CaCO}_{3}$-column to remove phosphate, arsenate $(\mathrm{As}(\mathrm{V}))$. Arsenite $(\mathrm{As}(\mathrm{III}))$ which was not retained on the column was oxidized to $\mathrm{As}(\mathrm{V})$. As(V) was converted into a heteropolymolybdenum blue anion. The blue anion was collected on a membrane filter as an ion-associate with $n$-dodecyltrimethylammonium ion by filtration. The filter was dissolved in $2 \mathrm{~mL}$ of 2 -methoxyethanol. The absorbance of the solution was measured at $810 \mathrm{~nm}$ against a reagent blank. Total inorganic arsenic was determined by reducing $\mathrm{As}(\mathrm{V})$ to $\mathrm{As}(\mathrm{III})$ before the column treatment. The RSDs for $10 \mu \mathrm{g} \mathrm{L}^{-1}$ of $\mathrm{As}(\mathrm{III})$ and $\mathrm{As}(\mathrm{V})$ were $2.9 \%$. Phosphate $0.2 \mathrm{mg} \mathrm{L}^{-1}$ (as P) and iron $0.1 \mathrm{mg} \mathrm{L}^{-1}$ did not interfere with the determination of $10 \mu \mathrm{g} \mathrm{L}^{-1}$ arsenic. The proposed method was successfully applied to ground waters.
\end{abstract}

(Received August 31, 2012; Accepted November 7, 2012; Published January 10, 2013)

\section{Introduction}

Pollution of drinking water with arsenic (As) is a serious problem in various countries in Asia and South America. Drinking water supplied from tube wells is contaminated with As in many areas. ${ }^{1-3}$ The WHO recommends a concentration of $10 \mu \mathrm{g} \mathrm{L}^{-1}$ as a safe level for drinking water. However, many countries where As contamination is serious including Bangladesh and India, adopt $50 \mu \mathrm{g} \mathrm{L}^{-1}$ as an interim standard. Therefore, the concentration of As in water must be monitored routinely to supply safe drinking water.

Arsenic in ground water occurs mainly as inorganic arsenite $(\mathrm{As}(\mathrm{III}))$ and arsenate $(\mathrm{As}(\mathrm{V}))$. It is essential to speciate these As species in addition to determining total arsenic, because the environmental chemical behavior and toxicity between As(III) and $\mathrm{As}(\mathrm{V})$ are quite different.

Hydride generation-atomic absorption spectrometry (HG-AAS) is useful for the determination of trace total arsenic. It requires, however, expensive instruments and a skillful operator. Moreover, it is not able to speciate As(III) and As(V). Therefore, there is a need for a simple, cost-effective and highly sensitive method for measuring As in drinking water supplied from ground water. Molybdenum blue (MB) spectrophotometry based on the reaction of $\mathrm{As}(\mathrm{V})$ with molybdate is a simple, rapid and cost-effective method for arsenic. However, it has two fatal problems that need to be resolved before it can be applied effectively for drinking water.

One of them is sensitivity. Sensitivity of the method is quite

$\dagger$ To whom correspondence should be addressed.

E-mail: taguchi@sci.u-toyama.ac.jp insufficient for determining of arsenic in drinking water. We proposed a sensitive MB spectrophotometry for phosphate where phosphomolybdenum blue anion was collected on a membrane filter (MF) as an ion-associate with a cationic surfactant and the MF was dissolved in a small volume of organic solvent. ${ }^{4,5}$ In the present study, this MF enrichment technique was employed to improve the sensitivity of the MB method for As.

Another problem with the MB method for As is considerable interference from phosphate. Phosphate also forms MB anion under the same conditions as for $\mathrm{As}(\mathrm{V})$. Matsubara et al. proposed a sensitive spectrophotometry for As based on the formation of an ion-associate between As-molybdate anion and Malachite Green cation combined with the soluble-MF technique. $^{6}$ In this technique, the total absorbance due to phosphate and $\operatorname{As}(\mathrm{V})$ was measured first, then the absorbance due to phosphate was subtracted from the total absorbance after $\mathrm{As}(\mathrm{V})$ was reduced to As(III), which is not detected by the MB method. This method is sensitive, but not useful when the concentration of phosphate is much higher than As.

Morita et al. proposed a spectrophotometry for trace arsenic using molybdate and ethyl violet. ${ }^{7,8}$ In this method, phosphate was removed by ion-exchange column before As-molybdate anion formation. This method was sensitive, but the color intensity due to ethyl violet decreased quickly with time. We researched other ways to remove phosphate from the sample solution before color development. We noticed the preconcentration of phosphate by coprecipitation with calcium carbonate. ${ }^{9}$ Calcium carbonate has a strong affinity to phosphate. Details of the retention of phosphate by calcium carbonate has been reported by Suzuki et al. and Sawada et al. ${ }^{10-12}$ In addition, $\mathrm{As}(\mathrm{V})$ also has a strong affinity to calcium carbonate, but As(III) 
has no affinity. ${ }^{13,14}$ These properties were taken for the separation and determination of $\mathrm{As}(\mathrm{III})$ and $\mathrm{As}(\mathrm{V})$ in the present study.

In this study, the sensitivity of the MB method was improved drastically by the MF enrichment technique, and the interference from phosphate and iron were eliminated by $\mathrm{CaCO}_{3}$-column treatment. The proposed method was applied to ground waters.

\section{Experimental}

\section{Reagents}

Molybdate solution for As(V) was dissolving $6 \mathrm{~g}$ of hexaammonium heptamolybdate tetrahydrate (Wako Pure Chemical Industries, Ltd.) and $0.24 \mathrm{~g}$ of potassium antimonyl tartrate (Wako Pure Chemical Industries, Ltd.) in $500 \mathrm{~mL}$ of $2.9 \mathrm{M}$ sulfuric acid. When $\mathrm{As}(\mathrm{III})$ is oxidized to $\mathrm{As}(\mathrm{V})$ in sulfuric acid solution before coloration, the concentration of the sulfuric acid for preparation of the molybdate solution should be 2.2 M. Hydrazinium sulfate solution was prepared by dissolving $1.35 \mathrm{~g}$ of hydrazinium sulfate (Wako Pure Chemical Industries, Ltd.) in $100 \mathrm{~mL}$ of water. A mixed reagent was prepared from $50 \mathrm{~mL}$ of the ammonium molybdate solution and $10 \mathrm{~mL}$ of the hydrazinum sulfate solution, and used within $20 \mathrm{~min}$. To make the $n$-dodecyltrimethylammonium bromide $\left(\mathrm{C}_{12} \mathrm{TMAB}\right)$ solution, $0.2 \mathrm{~g}$ of $\mathrm{C}_{12}$ TMAB (Tokyo Chemical Industry Co., Ltd.) was dissolved in $250 \mathrm{~mL}$ of water. The following procedure ${ }^{15}$ was carried out to remove the phosphate present as an impurity in this solution: add $2 \mathrm{~mL}$ of $6.5 \%$ aluminium chloride solution to the $\mathrm{C}_{12} \mathrm{TMAB}$ solution, adjust the $\mathrm{pH}$ to 8.5 with aqueous ammonia, and after mixing the solution for 25 min, remove the aluminium hydroxide by filtration. Potassium permanganate solution was prepared by dissolving $0.3 \mathrm{~g}$ of potassium permanganate in $100 \mathrm{~mL}$ of water. Calcium carbonate was obtained from Kanto Chemical Co., Ltd. of particle size $12-15 \mu \mathrm{m}$. All reagents used were of guaranteed grade.

\section{Apparatus}

A Hitachi Model U-2000A double-beam spectrophotometer was used to measure the absorbance. A Varian Model SpectrAA-55B with VGA-77 hydride generation-atomic absorption spectrometer (HG-AAS) was used for the determination of As in ground water samples. A Toyo A045A025A membrane filter $(0.45-\mu \mathrm{m}$ pore size, mixed cellulose esters, $25 \mathrm{~mm}$ diameter) and Toyo KG-25 filter support (effective filtration area $2.1 \mathrm{~cm}^{2}$ ) along with a funnel $(160 \mathrm{~mL}$ of volume) were used. $\mathrm{A} \mathrm{CaCO}_{3}$-column was prepared by packing the calcium carbonate powder to a polypropylene syringe (35 $\mathrm{mm}$ in diameter, $155 \mathrm{~mm}$ in length) as shown in Fig. 1. The column was connected to a filtration funnel and sealed with tape. A Toyo GS-25 glass-fiber filter was set at the downstream of the column system to retain very fine $\mathrm{CaCO}_{3}$ particles leaked from the column.

\section{Treatment with $\mathrm{CaCO}_{3}$ column before color development}

One hundred milliliters of sample solution containing less than $0.5 \mu \mathrm{g}$ of $\mathrm{As}(\mathrm{III})$ was taken. One milliliters of $0.1 \mathrm{M}$ calcium chloride solution was added to the sample solution. The solution was passed through the $\mathrm{CaCO}_{3}$-column under suction to remove $\mathrm{P}$ and $\mathrm{As}(\mathrm{V})$. Five milliliters of $0.1 \mathrm{M}$ calcium chloride solution was passed to wash out the As(III) remaining in the column. As(III) in the solution is determined by the following procedure.

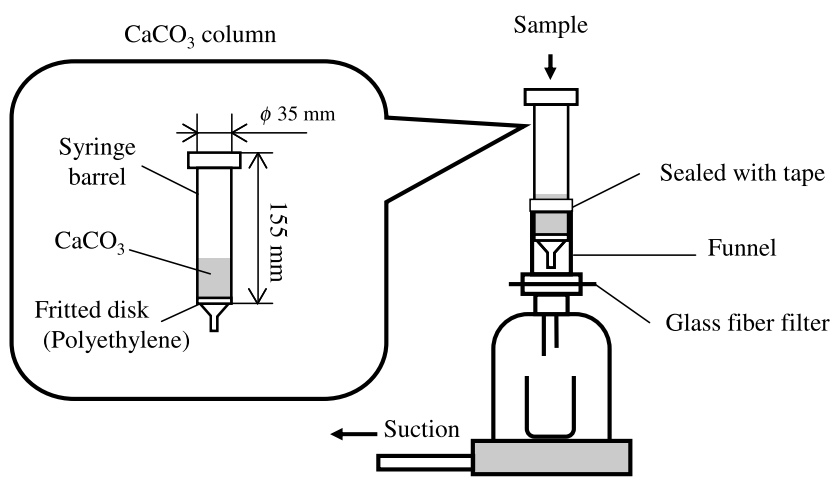

Fig. 1 Schematic drawing of calcium carbonate-column and filtration apparatus.

\section{Spectrophotometry for As(III)}

Two milliliters of $2.5 \mathrm{M}$ sulfuric acid were added to the sample solution. The potassium permanganate solution was added until the solution becomes light pink. The solution was set aside for 5 min to oxidize $\mathrm{As}(\mathrm{III})$ to $\mathrm{As}(\mathrm{V})$. Eight point eight milliliters of the mixed reagent was added to the solution. The solution was set aside for $15 \mathrm{~min}$ to form $\mathrm{MB}$ anion. One milliliter of the $\mathrm{C}_{12} \mathrm{TMAB}$ solution was added to the sample solution to form ion-associate with the MB anion. The solution was passed through a membrane filter to retain the ion-associate. The membrane filter was dissolved in $2 \mathrm{~mL}$ of 2 -methoxyethanol together with the ion-associate. The absorbance of the solution was measured at $810 \mathrm{~nm}$ against a reagent blank.

\section{Spectrophotometry for As(III) plus As(V)}

Two milliliters of $2.5 \mathrm{M}$ sulfuric acid and $0.05 \mathrm{~mL}$ of $0.08 \mathrm{M}$ sodium thiosulfate were added to $100 \mathrm{~mL}$ of sample solution. The solution was heated to boil to reduce $\mathrm{As}(\mathrm{V})$ to $\mathrm{As}(\mathrm{III})$. Ammonia solution was added to neutralize the solution. Determination of the As(III) formed was carried out by the same procedure as described above.

Application to ground water containing iron at high concentration When brown precipitate is observed in the $\mathrm{CaCO}_{3}$-column due to iron, following additional procedure described here is useful for preventing interference from iron. Acidified sample solution containing more than $0.5 \mu \mathrm{g}$ of arsenic and less than $0.1 \mathrm{mg}$ of iron was taken. The sample was diluted to $100 \mathrm{~mL}$ with pure water and added $1 \mathrm{~mL}$ of $\mathrm{Na}_{2} \mathrm{HPO}_{4}$ solution containing $10 \mathrm{mg} \mathrm{L}^{-1}$ of $\mathrm{P}$ to the diluted sample to mask iron. The solution was neutralized with ammonia to $\mathrm{pH}>7$ before column operation.

\section{Results and Discussion}

Reductant for color development and stability of the mixed reagent

Several reductants have been proposed for the formation of arsenomolybdenum blue anion. ${ }^{16,17}$ Color development was controlled by adjusting the concentrations of reductant and molybdate. In the present study, L-ascorbic acid and hydrazinium sulfate were investigated as reductants. In the case of $0.41 \mathrm{M}$ L-ascorbic acid and $12 \mathrm{mM}$ molybdenum, the absorbance increased with time and reached a constant after $20 \mathrm{~min}$. In the case of $1.7 \mathrm{mM}$ hydrazinium sulfate and $4.2 \mathrm{mM}$ molybdenum, absorbance reached a maximum at $10 \mathrm{~min}$ and a constant after 


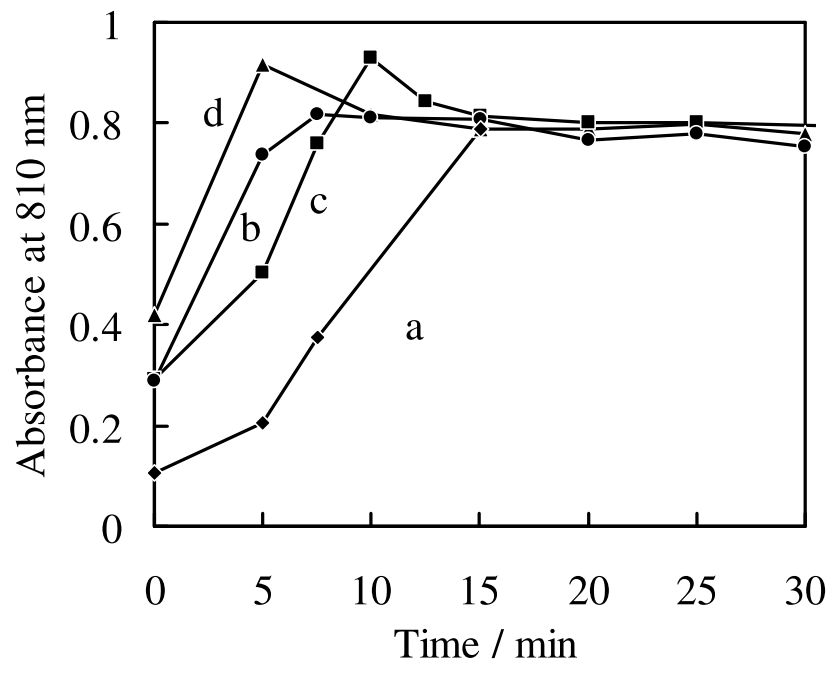

Fig. 2 Effect of the concentration of hydrazinium sulfate on color development. As(V), $8 \mu \mathrm{g}$ per $100 \mathrm{~mL}$; molybdenum, $4.2 \mathrm{mM}$. Hydrazinium sulfate: (a) 0.43 , (b) 1.3 , (c) 1.7 , (d) $2.1 \mathrm{mM}$.

$15 \mathrm{~min}$. The details of the effect of hydrazinium sulfate on color development are shown in Fig. 2. As can be seen, $1.3 \mathrm{mM}$ hydrazinium solution resulted in quick color development and stable absorbance within 10 min (line b in Fig. 2). Hydrazinium at high concentrations did not give stable absorbance at early reaction time as shown by lines $\mathrm{c}$ and $\mathrm{d}$ in Fig. 2. The reason for such unexpected results is not clear so far. To obtain constant and high absorbance, $1.3 \mathrm{mM}$ hydrazinium and $15 \mathrm{~min}$ of reaction time were recommended.

The mixed reagent must be used within $20 \mathrm{~min}$ after preparation because the absorbance decreased gradually as time elapsed. Within $20 \mathrm{~min}$, As was determined with less than $1 \%$ error.

\section{Absorption spectrum}

In this study, the absorbance was measured at the absorption maximum of $810 \mathrm{~nm}$. The reagent blank was negligible at the absorption maximum.

\section{Other conditions}

Other conditions, such as concentration of $n$-dodecyltrimethylammonium bromide $\left(\mathrm{C}_{12} \mathrm{TMAB}\right)$ solution added as a counter ion to the molybdenun blue anion, the material of the filter, filter size and pore size and the volume of the solvent to dissolve the filter were the same as in an earlier study conducted for phosphate. $^{5}$

\section{Calibration and reproducibility}

Linear calibration was obtained from 5 to $100 \mu \mathrm{g} \mathrm{L}^{-1}$ of $\mathrm{As}(\mathrm{III})$ and $\mathrm{As}(\mathrm{V})$ with a correlation coefficient of 0.999 . The detection limit and quantitation limit were $0.3 \mu \mathrm{g} \mathrm{L}^{-1}(3 \sigma)$ and $1.0 \mu \mathrm{g} \mathrm{L}^{-1}(10 \sigma)$, respectively. The RSDs for As(III), As(V) or $\mathrm{As}(\mathrm{III})+\mathrm{As}(\mathrm{V})$ at different concentrations are shown in Table 1 . Arsenite and arsenate were determined with satisfactory precision. Concentration of total As under different ratios of $\mathrm{As}(\mathrm{III})$ and $\mathrm{As}(\mathrm{V})$ were also determined with high recoveries.

$\mathrm{CaCO}_{3}$-column for the elimination of interference from phosphate

The performance of the $\mathrm{CaCO}_{3}$-column was investigated in the presence of calcium ion, because calcium ion drastically improved the performance of the column in preliminary
Table 1 Reproducibility for various arsenic concentrations $(n=5)$

\begin{tabular}{rrrrr}
\hline \multicolumn{2}{c}{$\begin{array}{c}\text { Concentration of As/ } \\
\mu \mathrm{g} \mathrm{L}^{-1}\end{array}$} & Absorbance at $810 \mathrm{~nm}$ & $\begin{array}{c}\text { RSD, } \\
\%\end{array}$ & $\begin{array}{c}\text { Recovery, } \\
\%\end{array}$ \\
$\mathrm{As}(\mathrm{V})$ & $\mathrm{As}(\mathrm{III})$ & & & \\
\hline & 5 & 0.036 & 3.6 & \\
& 10 & 0.076 & 2.9 & \\
& 40 & 0.333 & 3.1 & \\
& 80 & 0.677 & 1.3 & \\
& 100 & 0.889 & 1.2 & \\
5 & & 0.034 & 3.8 & \\
40 & & 0.073 & 2.9 & \\
80 & & 0.331 & 1.3 & \\
100 & & 0.685 & 1.2 & \\
20 & 80 & 0.889 & 1.8 & \\
50 & 50 & 0.903 & 1.7 & 102 \\
80 & 20 & 0.905 & 0.5 & 102 \\
& & 0.934 & 1.5 & 105 \\
\hline
\end{tabular}

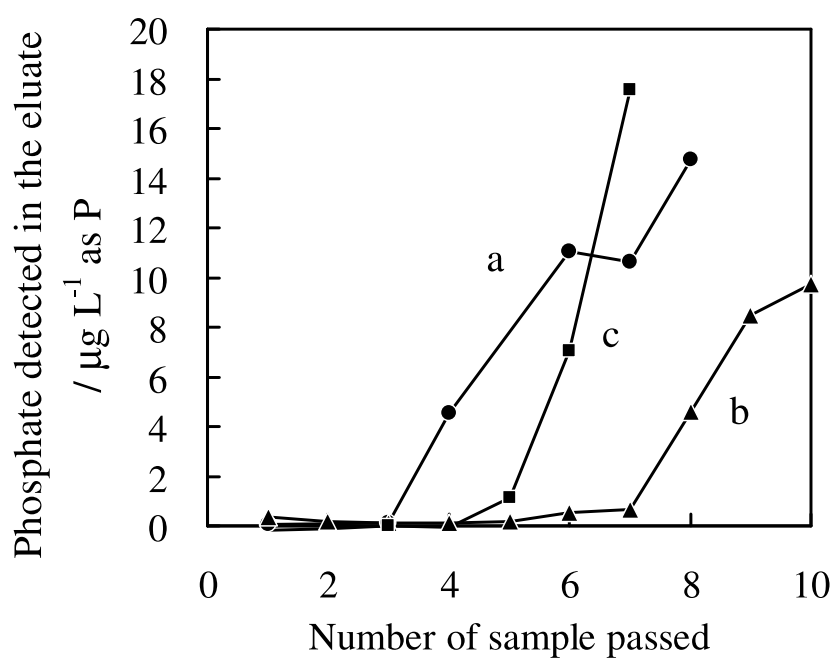

Fig. 3 Effect of calcium on the elimination of phosphate. Concentration of phosphate in the eluate after column operation of samples in the presence of $\mathrm{Ca}$ : (a) 0, (b) 0.001, (c) $0.01 \mathrm{M}$.

experiments.

Several samples of $100 \mathrm{~mL}$ containing $0.01 \mathrm{mg}$ of $\mathrm{P}$ as $\mathrm{Na}_{2} \mathrm{HPO}_{4}$ and $0,0.01$ or $0.1 \mathrm{M}$ calcium as $\mathrm{CaCl}_{2} \cdot 2 \mathrm{H}_{2} \mathrm{O}$ were prepared. They were passed through a column packed with $\mathrm{CaCO}_{3}$. The particle size and the amount of $\mathrm{CaCO}_{3}$ greatly affected the performance of the column. When $10 \mathrm{~g}$ of $\mathrm{CaCO}_{3}$ with $6 \mu \mathrm{m}$ particle diameter was used, the sample solution did not pass through the column at all due to clogging. And when $20 \mathrm{~g}$ of $\mathrm{CaCO}_{3}$ with $12-15 \mu \mathrm{m}$ diameter was used, more than 7 min was required to complete filtration. Ten grams of $\mathrm{CaCO}_{3}$ with $12-15 \mu \mathrm{m}$ diameter was recommended in this study, because $5 \mathrm{~min}$ was enough for filtration of a $100-\mathrm{mL}$ sample. After passing through the column, the phosphate in the solution was determined by the MB-MF spectrophotometry as described above. The performance and reusability of the column were also greatly effected by calcium ion. The results are shown in Fig. 3. In the absence of calcium, the column was usable only three times as shown by curve a in Fig. 3. On the other hand, in the presence of $0.001 \mathrm{M} \mathrm{Ca}$, the column was usable seven times as shown by curve $\mathrm{b}$ in Fig. 3. Clearly, $\mathrm{P}$ was removed 
Table 2 Interference from phosphate in the determination of arsenic $1 \mu \mathrm{g}$ of arsenic in $100 \mathrm{~mL}$ of sample $(n=3)$

\begin{tabular}{|c|c|c|}
\hline $\begin{array}{l}\text { Concentration of phosphate/ } \\
\qquad \mathrm{mg} \mathrm{L}^{-1} \text { as } \mathrm{P}\end{array}$ & Absorbance at $810 \mathrm{~nm}$ & $\begin{array}{c}\text { Recovery of As, } \\
\%\end{array}$ \\
\hline 0 & $0.076 \pm 0.002$ & \\
\hline 0.05 & $0.072 \pm 0$ & 95 \\
\hline 0.07 & $0.076 \pm 0.002$ & 100 \\
\hline 0.1 & $0.074 \pm 0.003$ & 97 \\
\hline 0.2 & $0.071 \pm 0.001$ & 94 \\
\hline
\end{tabular}

efficiently with the $\mathrm{CaCO}_{3}$-column, and the column performance was greatly improved by the addition of Ca. However, $0.01 \mathrm{M}$ Ca limited the column performance as shown by curve $\mathrm{c}$ in Fig. 3. Therefore, $0.001 \mathrm{M}$ calcium chloride was recommended.

Suzuki et al. proposed the following equilibrium for the retention of phosphate on the surface of $\mathrm{CaCO}_{3} .{ }^{10}$

$$
\mathrm{Ca}^{2+}+\mathrm{HPO}_{4}{ }^{2-} \rightleftharpoons \mathrm{CaHPO}_{4} \text { (on the surface of } \mathrm{CaCO}_{3} \text { ) }
$$

We presume the roles of calcium carbonate and calcium ion for the retention of phosphate as follows: Calcium and carbonate ions are released from calcium carbonate (Eq. (2)). The hydrolysis of the carbonate ion forms $\mathrm{HCO}_{3}{ }^{-}$at the contiguous solution to the surface of calcium carbonate (Eq. (3)).

$$
\begin{aligned}
& \mathrm{CaCO}_{3}(\mathrm{~s}) \rightleftharpoons \mathrm{Ca}^{2+}+\mathrm{CO}_{3}{ }^{2-} \\
& \mathrm{CO}_{3}{ }^{2-}+\mathrm{H}_{2} \mathrm{O} \rightleftharpoons \mathrm{HCO}_{3}{ }^{-}+\mathrm{OH}^{-}
\end{aligned}
$$

The released $\mathrm{Ca}^{2+}$ and $\mathrm{OH}^{-}$promote the formation of $\mathrm{CaHPO}_{4}$ and the formation of $\mathrm{CaHPO}_{4}$ is accelerated by the $\mathrm{Ca}^{2+}$ added to the sample solution. However, a high concentration of additional $\mathrm{Ca}^{2+}$ prevents the dissolution of calcium carbonate (Eq. (2)), and the release of $\mathrm{OH}^{-}$is suppressed (Eq. (3)). In consequence, the performance of calcium carbonated is limited.

Table 2 shows the effect of $\mathrm{P}$ on the determination of As after the $\mathrm{CaCO}_{3}$-column treatment at different $\mathrm{P}$ concentrations. Phosphate at high concentrations $\left(<0.2 \mathrm{mg} \mathrm{L}^{-1}\right.$ as $\left.\mathrm{P}\right)$ did not interfere with the determination of $10 \mu \mathrm{g} \mathrm{L}^{-1}$ arsenic.

\section{$\mathrm{CaCO}_{3}$-column for the elimination of interference from iron}

Most of the ground water that is heavily polluted with arsenic in West Bengal is also polluted with a high concentration of Fe. This is because such pollution results from the dissolution of arsenopyrite (FeAsS). Iron(II) and iron(III) forms brown precipitate on the surface of $\mathrm{CaCO}_{3}$, and the recovery of As(III) decreased dramatically as shown by curve a in Fig. 4. Probably iron forms hydroxide and $\mathrm{As}(\mathrm{III})$ is coprecipitated with the hydroxide on the surface of $\mathrm{CaCO}_{3}{ }^{18}$

The effect of masking reagents was investigated to eliminate the interference from iron. EDTA, which forms stable complexes with many metals, prevented the formation of arsenomolybdate. Next, the effect of phosphate was investigated, because phosphate forms stable complexes with iron(II) and iron(III). A solution of $\mathrm{Na}_{2} \mathrm{HPO}_{4}$ was added to an acidified sample. The solution was neutralized with ammonia, and it was passed through the $\mathrm{CaCO}_{3}$-column. Figure 4 shows the effect of phosphate on the masking of $\mathrm{Fe}$ as iron(II) sulfate for the determination of $0.01 \mathrm{mg}$ of As in $100 \mathrm{~mL}$ solution. Without phosphate, $0.1 \mathrm{mg} \mathrm{L}^{-1} \mathrm{Fe}$ gave less than $50 \%$ recovery of As(III). On the other hand, in the case of $0.1 \mathrm{mg} \mathrm{L}^{-1} \mathrm{P}$, the recovery of As(III) was almost quantitative even in the presence

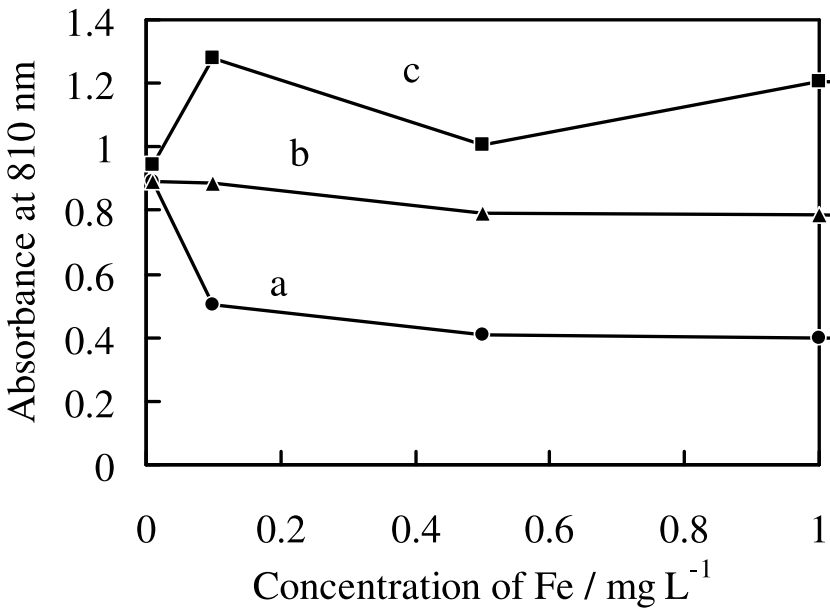

Fig. 4 Effect of phosphate on interference from iron. As(III), $0.01 \mathrm{mg}$ in $100 \mathrm{~mL}$ sample solution. P: (a) 0 , (b) 0.1 , (c) $0.5 \mathrm{mg} \mathrm{L}^{-1}$.

Table 3 Interference from foreign ions in the determination of arsenic $(n=3)$

\begin{tabular}{llcc}
\hline Ion & \multicolumn{1}{c}{ Added as } & $\begin{array}{c}\text { Concentration/ } \\
\mathrm{mg} \mathrm{L}^{-1}\end{array}$ & $\begin{array}{c}\text { Recovery, } \\
\%\end{array}$ \\
\hline $\mathrm{Na}^{+}$ & $\mathrm{NaCl}$ & 1000 & 106 \\
$\mathrm{~K}^{+}$ & $\mathrm{KCl}$ & 1000 & 106 \\
$\mathrm{Ca}^{2+}$ & $\mathrm{CaCl}_{2} \cdot 2 \mathrm{H}_{2} \mathrm{O}$ & 200 & 104 \\
$\mathrm{Mg}^{2+}$ & $\mathrm{MgCl}_{2} \cdot 6 \mathrm{H}_{2} \mathrm{O}$ & 100 & 108 \\
$\mathrm{Mn}^{2+}$ & $\mathrm{Mn}\left(\mathrm{NO}_{3}\right)_{2} \cdot 6 \mathrm{H}_{2} \mathrm{O}$ & 100 & 106 \\
$\mathrm{NH}_{4}{ }^{+}$ & $\mathrm{NH}_{4} \mathrm{Cl}$ & 2700 & 100 \\
$\mathrm{Cl}^{-}$ & $\mathrm{NaCl}^{-}$ & 1550 & 106 \\
$\mathrm{NO}_{3}{ }^{-}$ & $\left.\mathrm{Mn}^{-} \mathrm{NO}_{3}\right)_{2} \cdot 6 \mathrm{H}_{2} \mathrm{O}$ & 226 & 106 \\
$\mathrm{HCO}_{3}{ }^{-}$ & $\mathrm{Na}_{2} \mathrm{CO}_{3}$ & 100 & 103 \\
$\mathrm{SO}_{4}{ }^{2-}$ & $\mathrm{H}_{2} \mathrm{SO}_{4}$ & 4800 & 100 \\
\hline
\end{tabular}

of $0.1 \mathrm{mg} \mathrm{L}^{-1} \mathrm{Fe}$. Probably, iron was removed as complexes with phosphate, and the excess phosphate also adsorbed as $\mathrm{CaHPO}_{4}$ on the surface of $\mathrm{CaCO}_{3}$. However, $0.5 \mathrm{mg} \mathrm{L}^{-1} \mathrm{P}$ gave positive error (line $\mathrm{c}$ in Fig. 4). This was probably caused by the phosphate exceeded the sorption ability of $\mathrm{CaCO}_{3}$. The recovery of $10 \mu \mathrm{g} \mathrm{L}^{-1}$ As in the presence of $0.1 \mathrm{mg} \mathrm{L}^{-1}$ of $\mathrm{Fe}$ was also more than $98 \%$. Iron from 0.5 to $1 \mathrm{mg} \mathrm{L}^{-1}$ gave $88 \%$ recovery of $\mathrm{As}(\mathrm{III})$ in the presence of $0.1 \mathrm{mg} \mathrm{L}^{-1}$ of $\mathrm{P}$. The majority of As in ground water is supplied by dissolving iron-ore containing As. The pollution level of As comes up to $100 \mu \mathrm{g} \mathrm{L}^{-1}$, and that of iron sometimes reaches more than $10 \mathrm{mg} \mathrm{L}^{-1} \cdot{ }^{19-22} \mathrm{In}$ most cases, however, the ratio of $\mathrm{Fe}$ and As concentrations probably does not exceed 100. Therefore, dilution of the sample before the $\mathrm{CaCO}_{3}$-column operation is useful to prevent the interference from iron.

\section{Interferences from other ions}

Silicate and germanium also form molybdenum blues. Silicate at $30 \mathrm{mg} \mathrm{L}^{-1}\left(\right.$ as $\left.\mathrm{SiO}_{2}\right)$ did not interfere with the determination of As by the proposed method. In the case of germanium, the requisite concentration of molybdenum for color development ${ }^{23}$ is six times higher than that employed in this study. There are several reports staying the concentration level of germanium in ground water samples was $10 \mathrm{ng} \mathrm{L}^{-1}$ to $10 \mu \mathrm{g} \mathrm{L}^{-1} .^{24-26}$ Germanium is not likely to present at high concentrations to interfere. Table 3 shows the interference from other ions in the 
Table 4 Analytical results for arsenic in ground water and recovery tests $(n=3)$

\begin{tabular}{|c|c|c|c|c|c|}
\hline & \multicolumn{2}{|c|}{ As spiked } & \multirow{2}{*}{$\begin{array}{l}\text { As found } \\
\text { As Total/ } \\
\mu \mathrm{g} \mathrm{L}^{-1}\end{array}$} & \multirow{2}{*}{$\begin{array}{c}\text { Recovery of } \\
\text { As spiked } \\
\text { As total, } \\
\%\end{array}$} & \multirow{2}{*}{$\begin{array}{l}\text { HG-AAS/ } \\
\mu \mathrm{g} \mathrm{L}^{-1}\end{array}$} \\
\hline & $\begin{array}{c}\text { As(III)/ } \\
\mu \mathrm{g} \mathrm{L}^{-1}\end{array}$ & $\begin{array}{l}\mathrm{As}(\mathrm{V}) / \\
\mu \mathrm{g} \mathrm{L}{ }^{-1}\end{array}$ & & & \\
\hline \multirow{6}{*}{$\begin{array}{l}\text { University of } \\
\text { Toyama }\end{array}$} & None & None & $<1^{\mathrm{a}}$ & - & \multirow[t]{6}{*}{$<0.3^{\mathrm{b}}$} \\
\hline & 5 & 5 & $12 \pm 1.3$ & $116 \pm 11$ & \\
\hline & 15 & 15 & $27 \pm 0.9$ & $90 \pm 3.3$ & \\
\hline & 25 & 25 & $55 \pm 7.0$ & $109 \pm 13$ & \\
\hline & 40 & 40 & $74 \pm 0.5$ & $92 \pm 0.7$ & \\
\hline & 50 & 50 & $92 \pm 1.8$ & $92 \pm 1.9$ & \\
\hline \multirow[t]{6}{*}{ Toyama City } & None & None & $<1^{\mathrm{a}}$ & - & \multirow[t]{6}{*}{$<0.3^{\mathrm{b}}$} \\
\hline & 5 & 5 & $12 \pm 0.3$ & $120 \pm 2.3$ & \\
\hline & 15 & 15 & $27 \pm 0.7$ & $90 \pm 2.6$ & \\
\hline & 25 & 25 & $46 \pm 0.6$ & $92 \pm 1.4$ & \\
\hline & 40 & 40 & $71 \pm 0.9$ & $89 \pm 1.2$ & \\
\hline & 50 & 50 & $91 \pm 0.9$ & $91 \pm 1.0$ & \\
\hline
\end{tabular}

a. Lower than the quantitation limit $(10 \sigma)$.

b. Lower than the detection limit $(3 \sigma)$.

Table 5 Analytical results for arsenic(III) for ground water and recovery tests $(n=3)$

\begin{tabular}{|c|c|c|c|c|}
\hline & \multicolumn{2}{|c|}{ As spiked } & \multirow{2}{*}{$\begin{array}{l}\text { As found } \\
\text { As(III)/ } \\
\mu \mathrm{g} \mathrm{L}^{-1}\end{array}$} & \multirow{2}{*}{$\begin{array}{c}\text { Recovery of } \\
\text { As spiked } \\
\text { As total, } \\
\%\end{array}$} \\
\hline & $\begin{array}{c}\mathrm{As}(\mathrm{III}) / \\
\mu \mathrm{g} \mathrm{L}^{-1}\end{array}$ & $\begin{array}{l}\mathrm{As}(\mathrm{V}) / \\
\mu \mathrm{g} \mathrm{L}^{-1}\end{array}$ & & \\
\hline \multirow[t]{7}{*}{ University of Toyama } & None & None & $<1^{\mathrm{a}}$ & - \\
\hline & 10 & 10 & $5 \pm 1.9$ & $52 \pm 38$ \\
\hline & 10 & 10 & $9 \pm 0.5^{\mathrm{b}}$ & $91 \pm 5.2^{\mathrm{b}}$ \\
\hline & 30 & 30 & $29 \pm 2.2^{\mathrm{b}}$ & $96 \pm 7.6^{b}$ \\
\hline & 50 & 50 & $50 \pm 2.2^{\mathrm{b}}$ & $99 \pm 4.5^{\mathrm{b}}$ \\
\hline & 80 & 80 & $80 \pm 4.2^{b}$ & $100 \pm 5.2^{\mathrm{b}}$ \\
\hline & 100 & 100 & $99 \pm 16.6^{b}$ & $99 \pm 17^{\mathrm{b}}$ \\
\hline \multirow[t]{6}{*}{ Toyama City } & None & None & $<1^{\mathrm{a}}$ & - \\
\hline & 10 & 10 & $11 \pm 1.0$ & $108 \pm 9.6$ \\
\hline & 30 & 30 & $28 \pm 2.8$ & $94 \pm 9.8$ \\
\hline & 50 & 50 & $55 \pm 3.4$ & $109 \pm 6.3$ \\
\hline & 80 & 80 & $88 \pm 10$ & $110 \pm 11$ \\
\hline & 100 & 100 & $90 \pm 9.4$ & $90 \pm 10$ \\
\hline
\end{tabular}

a. Lower than the quantitation limit $(10 \sigma)$

b. Sodium thiosulfate was added before $\mathrm{CaCO}_{3}$-column operation.

determination of As. The concentrations of the foreign ions were set up to almost the same or higher levels as those in ground water sampled in Bengali. ${ }^{19}$ Arsenic was recovered quantitatively in the presence of these ions.

\section{Application to ground water}

The proposed method was applied to ground water samples collected in Toyama City and at University of Toyama. Table 4 shows the analytical results of total arsenic for the samples with and without the addition of $\mathrm{As}(\mathrm{III})$ and $\mathrm{As}(\mathrm{V})$. The total As in a sample without additional As was determined by HG-AAS. The analytical results by the proposed method and HG-AAS for these samples were below the quantitation limit of $1 \mu \mathrm{g} \mathrm{L}^{-1}$ $(10 \sigma)$ and detection limit of $0.3 \mu \mathrm{g} \mathrm{L}^{-1}(3 \sigma)$. The recoveries of the total As spiked in these water samples were satisfactory. Table 5 shows the analytical results for As(III). In the case of ground water samples taken from the University of Toyama, the recovery of As(III) was only 52\%. At the University of Toyama, hypochlorite was added as antiseptic to ground water before supplying as tap water. Probably, parts of As(III) spiked to the water were oxidized to $\mathrm{As}(\mathrm{V})$ by hypochlorite and removed with the $\mathrm{CaCO}_{3}$-column. Therefore, addition of thiosulfate to the ground water was examined to reduce the activity of the hypochlorite. When $0.05 \mathrm{~mL}$ of $0.08 \mathrm{M}$ sodium thiosulfate was added to the ground water, the activity of hypochlorite was eliminated without any reduction of $\mathrm{As}(\mathrm{V})$. Probably, this successful result came from that the reduction of $\mathrm{As}(\mathrm{V})$ with thiosulfate is performed only under strongly acidic medium. The recoveries of As(III) increased to range from 91 to $100 \%$ by this method. In the case of Toyama City ground water which did not contain hypochlorite, recoveries of As(III) ranged from 90 to $109 \%$ without the addition of thiosulfate. These results show that foreign species in ground water did not interfere with the determination of As.

\section{Conclusions}

A simple and cost-effective analytical method for the determination of As in water was proposed. The preconcentration technique with membrane filter improved sensitivity, and the $\mathrm{CaCO}_{3}$-column was effective for eliminating interference from phosphate. The speciation of $\mathrm{As}(\mathrm{III})$ and $\mathrm{As}(\mathrm{V})$ was also performed by the proposed method. Thirty minutes was enough for the entire procedure for As(III) from column operation to absorbance measurement, and $40 \mathrm{~min}$ for total As. This method will be useful for monitoring drinking water and environmental water, and also for screening for arsenic before instrumental analysis such as AAS and ICP-AES.

\section{Acknowledgements}

The authors would like to thank Dr. M. Tafu, Ecotechnology Laboratory, Toyama National College of Technology, for the use of HG-AAS equipment. This work was partly supported financially by Kyoritsu Chemical-Check Lab., Corp.

\section{References}

1. B. K. Mandal, T. R. Chowdhury, G. Samanta, G. K. Basu, P. P. Chowdhury, C. R. Chanda, D. Lodh, N. K. Karan, R. K. Dhar, D. K. Tamili, D. Das, K. C. Saha, and D. Chakraborti, Curr. Sci., 1996, 70, 976.

2. D. K. Nordstrom, Science, 2004, 296, 2143.

3. P. L. Smedley and D. G. Kinniburgh, Appl. Geochem., 2002, 17, 517.

4. S. Taguchi, E. Ito-oka, and K. Goto, Bunseki Kagaku, 1984, 33, 453.

5. S. Taguchi, E. Ito-oka, K. Masuyama, I. Kasahara, and K. Goto, Talanta, 1985, 32, 391.

6. C. Matsubara, Y. Yamamoto, and K. Takamura, Analyst, 1987, 112, 1257.

7. K. Morita and E. Kaneko, Anal. Sci., 2006, 22, 1085.

8. K. Morita and E. Kaneko, Anal. Chem., 2006, 78, 7682.

9. H. Kawamoto and H. Akaiwa, Bunseki Kagaku, 1987, 36, 805.

10. T. Suzuki, S. Inomata, and K. Sawada, J. Chem. Soc. Faraday Trans. 1, 1986, 82, 1733.

11. K. Sawada, S. Yoshida, and T. Suzuki, J. Chem. Soc. Faraday Trans., 1992, 88, 2227.

12. K. Sawada, N. Adbel-Aal, H. Sekino, and K. Satoh, Dalton Trans., 2003, 342. 
13. H. U. S $\varnothing$, D. Postma, R. Jakobsen, and F. Larsen, Geochim. Cosmochim. Acta, 2008, 72, 5871.

14. V. G. Alexandratos, E. J. Elzinga, and R. J. Reeder, Geochim. Cosmochim. Acta, 2007, 71, 4172.

15. M. Aoyama, T. Hobo, and S. Suzuki, Anal. Chim. Acta, 1983, 153, 291.

16. D. Rogers and A. E. Heron, Analyst, 1946, 71, 414.

17. H. Magnuson and E. Watson, Ind. Eng. Chem., Anal. Ed., 1944, 16, 339.

18. D. Mohan and C. U. Pittman Jr., J. Hazard. Mater., 2007, $142,1$.

19. D Stuben, Z. Berner, D. Chandrasekharam, and J. Karmakar, Appl. Geochem., 2003, 18, 1417.

20. P. Ravenscroft, W. G. Burgess, K. M. Ahmed, M. Burren, and J. Perrin, Hydrogeol. J., 2005, 13, 727.

21. R. T. Nicksona, J. M. McArthura, P. Ravenscroftb, W. G.
Burgessa, and K. M. Ahmed, Appl. Geochem., 2000, 15, 403.

22. A. Geen, Y. Zheng, S. Goodbred, Jr., A. Horneman, Z. Aziz, Z. Cheng, M. Stute, B. Mailloux, B. Weinman, M. A. Hoque, A. A. Seddique, M. S. Hossain, S. H. Chowdhury, and K. M. Ahmed, Environ. Sci. Technol., 2008, 42, 2283.

23. D. F. Boltz and M. G. Mellon, Anal. Chem., 1947, 19, 873.

24. P. L. Smedley, H. B. Nicolli, D. M. J. Macdonald, A. J. Barros, and J. O. Tullio, Appl. Geochem., 2002, 17, 259.

25. C. Reimann, K. Bjorvatn, B. Frengstad, Z. Melaku, R. Tekle-Haimanot, and U. Siewers, Sci. Total Environ., 2003, 311,65 .

26. I. M. Farnham, K. H. Johannesson, A. K. Singh, V. F. Hodge, and K. J. Stetzenbach, Anal. Chim. Acta, 2003, 490, 123 . 